\title{
Influence of Electron Beam Irradiation on the Impact Value of Alkali Free Glass*1
}

\author{
Yoshitake Nishi and Keisuke Iwata*2 \\ Graduate school of Materials Science, Tokai University, Hiratsuka 259-1292, Japan
}

Influences of electron beam irradiation on impact fracture energy indicated by impact value are studied for alkali free glass. The irradiation, which is able to be one of short-time treatments, reduced the brittleness and increased the impact value of alkali free glass. The impact value enhancement can be explained by stress relaxation induced by increase in density of dangling bonds. [doi:10.2320/matertrans.47.1810]

(Received December 8, 2005; Accepted May 26, 2006; Published July 15, 2006)

Keywords: electron beam, impact value, alkali free glass, dangling bond, minimum impact fracture value

\section{Introduction}

Low-energy electron beam (EB) irradiation, is generally a successful industrial surface treatment to apply to enhance hardening and wear resistance of polymer. EB-strengthening methods, caused by annihilation of dangling bonds, have been established for carbon fiber $(\mathrm{CF})$, carbon-deposited carbon fiber $(\mathrm{C} / \mathrm{C})$ composite materials and carbon fiber reinforced polymer (CFRP). ${ }^{1-4)}$ To enable freedom from misting and easy sterilization of ceramics, EB irradiation techniques are presently being developed to assist production of dentists' mirrors, sapphire lenses and diamond windows for endoscope ${ }^{5-7)}$ Thus, EB-irradiation is a useful tool to create attractive multi-functional properties.

On the other hand, another effect of EB irradiation is homogeneous activation of surface atoms and breaking of chemical bonds between the $\mathrm{Si}-\mathrm{O}$ pairs, that is a dangling bond, ${ }^{8,9)}$ in the network structure of a surface layer of silica glass, ${ }^{10)}$ inducing resistance to fracture under loading in the tightly bonded network structure of silica glass. ${ }^{10)}$ To shorten the treatment time, addition of alkali metals is a useful tool because of high formation rate of dangling bond by EB irradiation. Thus, influences of EB irradiation on mechanical properties have been investigated of soda glass. ${ }^{112)} \mathrm{EB}$ irradiation enlarges the static bending fracture stress and enhances the rigidity. When EB irradiation generates dangling bonds at the weakly bonded metal-oxygen atomic pairs in the soda glass network structure, partial relaxation occurs at points of residual strain in the network structure. It is clear that the increased rigidity is mainly due to an increase in the bonding energy of the silicon-oxygen atomic pairs in the atomic network structure. ${ }^{11,12)}$ Knowledge of the Charpy impact value is important for practical use. When EB irradiation generates dangling bonds at weakly bonded metaloxygen pairs and thus relaxes the network structure of soda glass, ${ }^{12)}$ it also enhances its impact value.

The strength of transparent thin glass sheet is one of important points to be used in process engineering for wide screen liquid crystal TVs. The transparent alkali-free glasses,

\footnotetext{
*1 This Paper was Originally Published in Japanese in J. Japan Inst. Metals 69 (2005) 1016-1020

${ }^{* 2}$ Graduate Student, Tokai University
}

which alkali metals do not contaminate the liquid-crystal solution, act as an electrical insulator. However, the fracture toughness of the thin sheet for the liquid crystal TVs is a serious problem to be used in process engineering. Since the atom fractions of alkali earth metals are from 3.1 to 5.6 in the alkali free glass with the small atom fractions below 0.5 at $\%$ of weakly bonded metals, the dangling bond formation by EB-irradiation has been also expected in alkali free glass. If EB irradiation generates dangling bonds at alkali earth metaloxygen pairs and thus relaxes the network structure of alkali free glass, it may enhance its impact value. To confirm if it is possible to strengthen transparent thin glass sheets of the type to be used in process engineering for wide screen liquid crystal TVs, we have undertaken the present study to investigate the possible beneficial effects of EB irradiation on the impact value of alkali free glass. Furthermore, to clarify the results, ESR observations are used to confirm the existence of dangling bonds.

\section{Experimental}

\subsection{Samples preparation for impact test}

The sizes of our alkali free glass samples (AN100, Asahi Glass CO. Ltd., Japan) were $20 \mathrm{~mm} \times 10 \mathrm{~mm} \times 1.0\left(\mathrm{~mm}^{3}\right)$. An ESCA analysis (time/step: $40 \mathrm{~ms}$, probe diameter: 100 $\mu \mathrm{m}$, pass potential: $23.5 \mathrm{eV}$, step: $0.1 \mathrm{eV}$, sweeps $20,1 \mathrm{kV}-$ $30 \mathrm{~s})$ showed the chemical composition ratio of their metal elements $(\mathrm{Si}: \mathrm{Al}: \mathrm{Ca}: \mathrm{Sr}: \mathrm{Ba}: \mathrm{Na}: \mathrm{Zn})$ to be $71.8: 18.6$ : $5.6: 3.1: 0.5: 0.3: 0.1$, respectively.

\subsection{Electron beam (EB) irradiation}

The glass sheets were homogeneously irradiated using an electron-curtain processor (Type CB175/15/180L, Energy Science Inc., Woburn, MA, Iwasaki Electric Group Co. Ltd. Tokyo). ${ }^{2-7)}$ The specimen was homogeneously irradiated with the electron beam through a titanium thin film window attached to the vacuum chamber, $240 \mathrm{~mm}$ in diameter. A tungsten filament in vacuum was used to generate the electron beam at an acceleration potential of $170 \mathrm{kV}$ and irradiating current of $2.0 \mathrm{~mA}$. To prevent oxidation, the samples were kept nitrogen gas of $1 \mathrm{~atm}$ with a residual concentration of oxygen of below $400 \mathrm{ppm}$. The flow rate of the nitrogen gas was $1.5 \mathrm{~L} / \mathrm{s}$ at $0.1 \mathrm{MPa}$. Each dose $(0.0432$ 
MGy) of EB irradiation was applied for only a short time $(0.23 \mathrm{~s})$ to avoid excessive heating of the sample; the temperature of the sample surface remained below $323 \mathrm{~K}$ just after irradiation. The sample in the aluminum plate holder $(0.15 \mathrm{~m} \times 0.15 \mathrm{~m})$ was transported on a conveyor at a speed of $9.56 \mathrm{~m} / \mathrm{min}$. Repetitive applications to both sides surface of samples were used to increase the total dose of irradiation. The interval between the end of one period of irradiation and the start of the next was $30 \mathrm{~s}$. The dosage was proportional to the yield value determined from the irradiation current, the conveyor speed and number of irradiations. The yield value was calibrated by FWT nylon dosimeters (Far West Technology, Inc. 330-D South Kellogg Goleta, California 93117, California). Based on the density ( $\rho$ : $\left.\mathrm{kg} / \mathrm{m}^{3}\right)$ and irradiation voltage $(\mathrm{V}: \mathrm{kV})$, the EB irradiation depth $\left(D_{\mathrm{th}}: \mathrm{m}\right)$ was expressed by the following equation. ${ }^{13)}$

$$
D_{\text {th }}=66.7 V^{5 / 3} / \rho
$$

The surface electrical potential $(128 \mathrm{keV})$ was estimated from the electrical potential $(170 \mathrm{keV})$, thickness of the titanium window $\left(10 \mu \mathrm{m}\right.$; density: $\left.4540 \mathrm{~kg} / \mathrm{m}^{3}\right)$ and the distance in the nitrogen gas atmosphere $(30 \mathrm{~mm}$; density: 1.13 $\mathrm{kg} / \mathrm{m}^{3}$ ) between the sample and the window. Since the measured density for alkali free glass was $2430 \mathrm{~kg} / \mathrm{m}^{3}$, the EB irradiation depth estimated from eq. (1) should have been $9.16 \times 10^{-5} \mathrm{~mm}$ for this material.

\subsection{Impact test to measure impact value}

To evaluate the impact fracture toughness, the Charpy impact values of the glasses with and without EB irradiation were measured using a standard impact fracture energy measurement system (JIS K 7077-1991). The Charpy impact value was expressed by the following equation.

$$
\begin{aligned}
E= & W R[(\cos \beta-\cos \alpha) \\
& \left.-\left(\cos \alpha^{\prime}-\cos \alpha\right)(\alpha+\beta) /\left(\alpha-\alpha^{\prime}\right)\right]
\end{aligned}
$$

Here, $\mathrm{E}, \mathrm{W}, \mathrm{R}, \beta, \alpha$ and $\alpha^{\prime}$ were impact fracture energy $(\mathrm{kJ})$, hammer mass $(\mathrm{N})$, length $(\mathrm{m})$ of hammer weight point from rolling center, start angle before impact, the maximum angle after impact and the maximum angle of the blank test, respectively. The Charpy impact value $\left(\mathrm{kJ} \mathrm{m}^{-2}\right)$ was expressed by the following equation.

$$
a_{u c}=E /(b \times t)
$$

Here, $E, b(=1.00 \pm 0.005 \mathrm{~mm})$ and $t(=20 \mathrm{~mm})$ were impact fracture energy $(\mathrm{J})$, sample width $(\mathrm{mm})$ and span distance (sample thickness, $\mathrm{mm}$ ), respectively. The distance between supporting points was $11.45 \mathrm{~mm}$.

\subsection{Evaluation of dangling bonds}

To obtain more precise information on atomic-scale structural changes in the glass, the density of the dangling bonds was obtained using an electron spin resonance spectrometer (ESR, JES-FA2000, Nippon Denshi Ltd., Tokyo). ${ }^{10)}$ The microwave frequency range used in the ESR analysis was the X-band at $9.45 \pm 0.05 \mathrm{GHz}$, with a field modulation of $100 \mathrm{kHz}$. The microwave power was $1 \mathrm{~mW}$. The magnetic field was varied from 318.7 to $328.7 \mathrm{mT}$. The spin density was calculated using a $\mathrm{Mn}^{2+}$ standard sample. No spin densities are given, but ESR spectra.

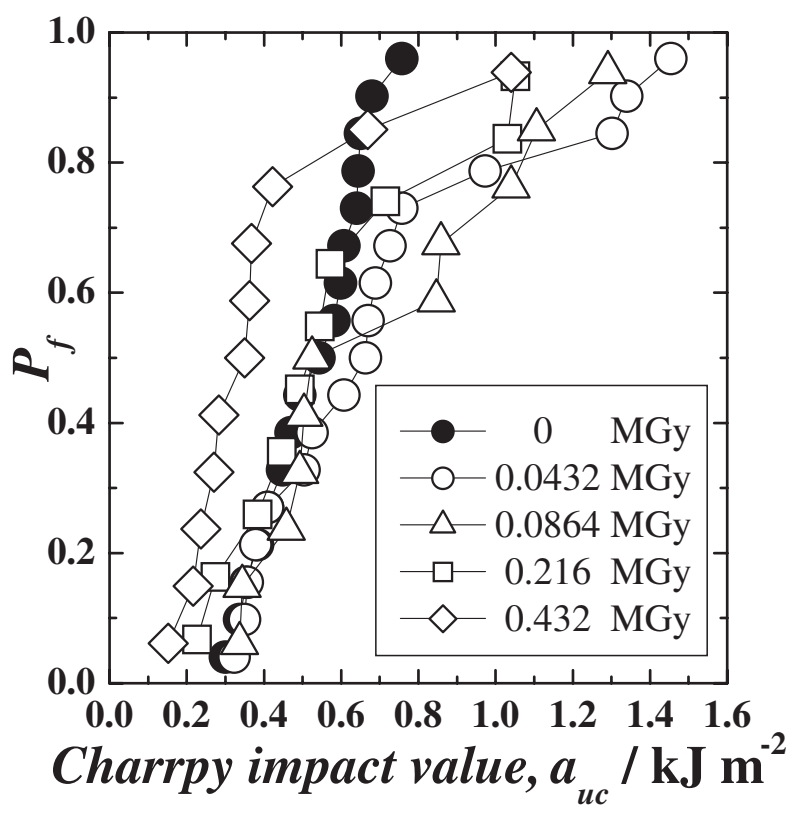

Fig. 1 Relationships between Charpy impact value $\left(\mathrm{kJ} \mathrm{m}^{-2}\right)$ of alkali free glass and fracture probability.

\section{Results}

\subsection{Impact value of alkali free glass before and after EB- irradiation}

An integrated fracture probability $\left(P_{f}\right)$ is a convenient way to analyze fracture stress value $\left(\sigma_{f}\right)$ quantitatively, and is expressed by the following equation which uses a generalized form of the Median Rank method. ${ }^{14)}$

$$
P_{f}=(I-0.3) /(n+0.4)
$$

Here, $n$ and $I$ are the total number of samples and the order of fracture of each sample, respectively. If the $P_{f}$ value is applied for impact value, the relationships between the Charpy impact value of alkali free glass at different EB irradiation dosages and fracture probability are shown in Fig. 1. The electron beam irradiation from 0.0432 to 0.0864 MGy enhances the impact value of alkali free glass at different fracture probabilities.

Although the impact values of $0.216 \mathrm{MGy}$-irradiated samples are approximately equal to those before irradiation below 0.6 of $P_{f}$, the measured impact values of the samples of $0.216 \mathrm{MGy}$-irradiation above 0.7 of the higher fracture probability also are higher than that before irradiation. Excess EB irradiation above $0.432 \mathrm{MGy}$ clearly decreases the impact values below 0.8 of $P_{f}$, resulting in the embitterment of alkali free glass similar to those before irradiation, whereas the measured impact values of the $0.432 \mathrm{MGy}$-irradiated samples above 0.8 of the higher fracture probability also are higher than that before irradiation.

\subsection{Dangling bond formation}

From the general X-ray diffraction patterns of the alkali free glass before and after the EB irradiation, no marked structure changes can be observed. On the other hand, EB irradiation produces detectable dangling bonds. To discuss the influences of electron beam irradiation on the Charpy 


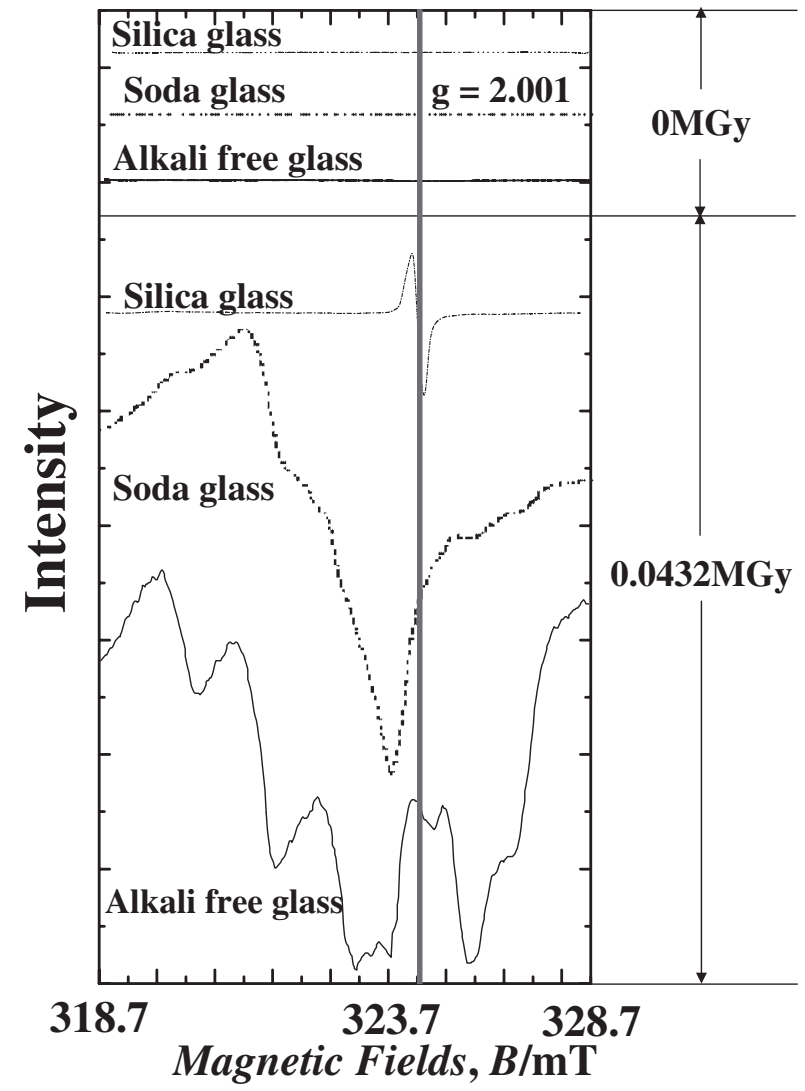

Fig. 2 ESR signals of silica, soda and alkali free glasses before and after EB irradiation.

impact values, ESR signals related to dangling bonds have been observed. Figure 2 shows the ESR signals of alkali free, soda and silica glasses before and after $0.0432 \mathrm{MGy}-\mathrm{EB}$ irradiation. Although no ESR signals are found in these glasses before EB irradiation, a high density of dangling bonds are noted in these irradiated glasses. However, all irradiated glasses show different peak heights and different magnetic field values of the top peak of ESR signals.

\section{Discussion}

\subsection{Influences of EB irradiation on the impact values of alkali free glass}

If the Weibull Equation is assumed to be applicable to the measured Charpy impact value $\left(a_{u c}\right),{ }^{15)}$ the fracture probability $\left(P_{f}\right)$ depends on the risk of rupture $\left(\left[a_{u c}-a_{s}\right] / a_{o}\right)$.

$$
P_{f}=1-\exp \left[-\left(\left(a_{u c}-a_{s}\right) / a_{o}\right)^{m}\right]
$$

In predicting the required impact value of the new structural materials, the Weibull coefficient $(m)$, the expectant impact value $\left(a_{o}\right)$ and the lowest value of impact value $\left(a_{s}\right)$ are key parameters. When the $P_{f}$ values are equal to 0.967 and 0 , respectively, the $a_{u c}$ values are defined as $a_{o}$ and $a_{s}$, as shown in Fig. 3. Figure 3 shows changes in the correlation coefficient $(\mathrm{F})$ with respect to the potential lowest value of the impact value $\left({ }^{e} a_{s}\right)$. The lowest value of the impact value $\left(a_{s}\right)$, applied in the Weibull equation, is determined. When a correlation coefficient $(F)$ shows the maximum value, the $a_{s}$ can be obtained, as shown in Fig. 3. The $a_{s}$ values at 0, 0.043,

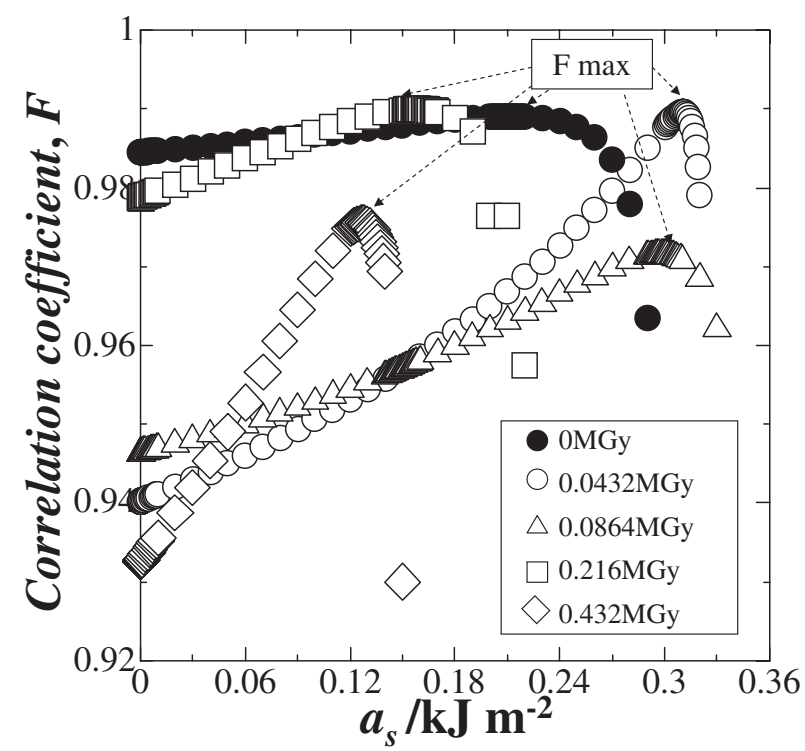

Fig. 3 Change in correlation coefficient (F) against the estimated lower limit value of impact value $\left(a_{s}\right)$ of alkali free glass.

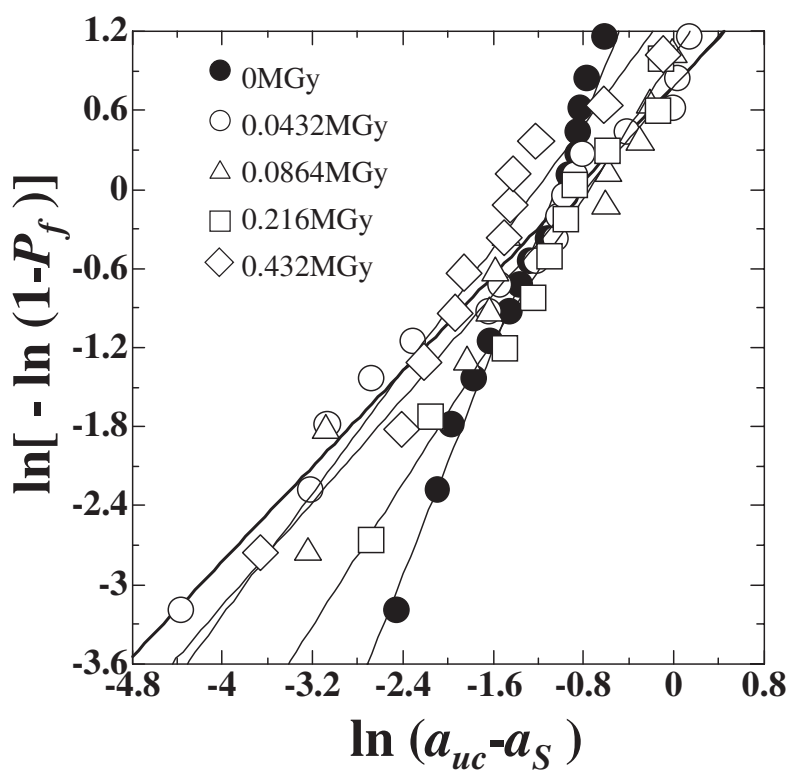

Fig. 4 Weibull plots of alkali free glass irradiated by electron beam at different dosage.

0.086, 0.216 and $0.432 \mathrm{MGy}$ are $0.214,0.308,0.298,0.158$ and 0.127 , respectively. Figure 4 shows Weibull plots of alkali free glass irradiated by the electron beam at different dosages. Linear relationships are obtained. Thus, the required impact values can be obtained at the expected fracture probabilities.

Changes in the impact values at the calculated fracture probabilities $\left(P_{f}=0\left(a_{s}\right), 0.033\right.$ and 0.5$)$ with respect to EB irradiation dosages are also shown in Fig. 5. The EB irradiation below $0.0432 \mathrm{MGy}$ increases the calculated impact values at $0\left(a_{s}\right), 0.033$ and 0.5 of $P_{f}$, resulting in reliability enhancement related to impact strengthening for alkali free glass. The $a_{s}$ value of $0.0432 \mathrm{MGy}$-irradiated alkali free glass is $44 \%$ higher than that before irradiation. 


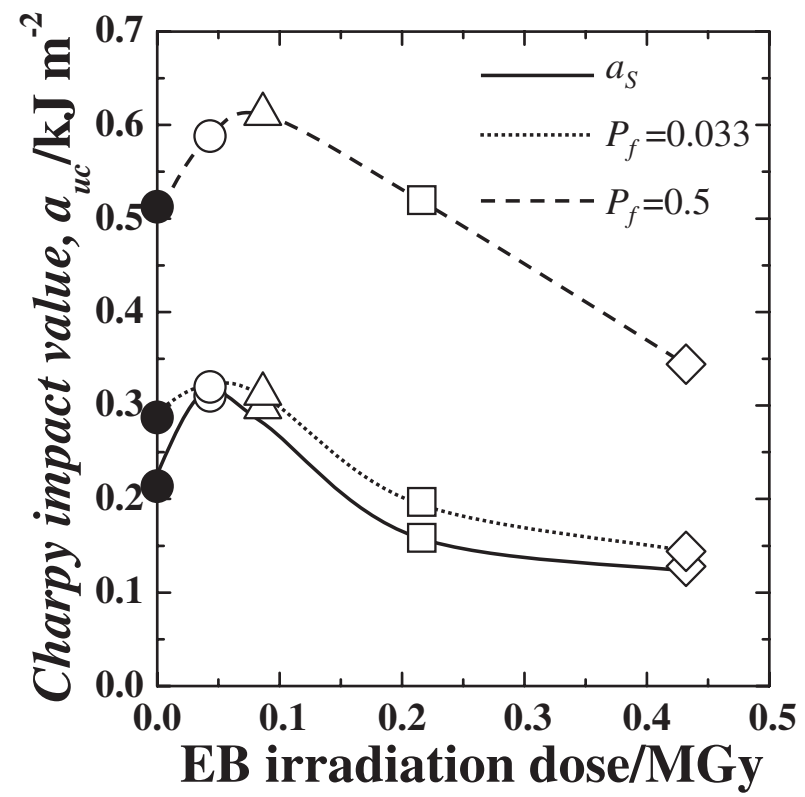

Fig. 5 Change in the impact value of alkali free glass against EB irradiation dose at different fracture probabilities.

The impact values of the electron beam irradiated alkali free glass from 0.0432 to $0.864 \mathrm{MGy}$ are always higher than those before EB irradiation, although excess EB irradiation above $0.0864 \mathrm{MGy}$ decreases the impact values.

\subsection{Dangling bonds formation in alkali free glass}

As shown in Fig. 5, we have also noted an enhancement of impact value at $0\left(a_{s}\right), 0.033$ and 0.5 of $P_{f}$ after $0.0432 \mathrm{MGy}-$ irradiation of alkali free glass. The impact value after $0.0432 \mathrm{MGy}-\mathrm{EB}$ irradiation at $0\left(a_{s}\right)$ of $P_{f}$ are 1.5 times higher than that before irradiation. The $0.0432 \mathrm{MGy}-\mathrm{EB}$ irradiation increases the impact values of the glass to a level about $50 \%$ above that of the sample before irradiation. Thus, the impact values are controlled by the EB irradiation, as assumed after casting.

If the annealed structure of the alkali free glass is a tightly bonded network, the glass is brittle. On the other hand, EB irradiation provides the 794, 507, 422, 398, 558, 267 and $252 \mathrm{~kJ} / \mathrm{mol}$ of energy necessary to break the chemical bonds between $\mathrm{Si}, \mathrm{Al}, \mathrm{Sr}, \mathrm{Ca}, \mathrm{Ba}, \mathrm{Zn} \mathrm{Na-O}$ pairs, respectively. ${ }^{16)}$ If the partial relaxation of the molecular residual strain in the silica glass network structure is due to the EB-created dangling bonds from weaker bonded metal-oxygen pairs, as shown in Fig. 2, the EB irradiation probably relaxes the glassy network structure and as a result enhances the impact values.

Based on ESR results, shown in Fig. 2, irradiated alkalifree soda and silica glasses form different type of dangling bonds. A sharp ESR signal is observed in the irradiated silica glass $^{10)}$ corresponding to dangling bonds of an E-prime center consisting of an Si-O pair. ${ }^{8,9)}$ Large ESR signals are observed in the irradiated soda glass ${ }^{12}$ corresponding to dangling bonds of weakly-bonded metal ( $\mathrm{Na}, \mathrm{Zn}, \mathrm{K}$ )-oxygen pairs. The bond strength (398 and $422 \mathrm{~kJ} / \mathrm{mol})^{16)}$ of alkaline earth metal ( $\mathrm{Ca}$ and $\mathrm{Sr}$ )-oxygen pairs is stronger than that $(252,267 \text { and } 275 \mathrm{~kJ} / \mathrm{mol})^{16)}$ of the weaker oxygen bonds formed by the alkali metals ( $\mathrm{Na}, \mathrm{Zn}, \mathrm{K})$ and weaker than that $(796 \text { and } 507 \mathrm{~kJ} / \mathrm{mol})^{16)}$ of the stronger bonds of the ( $\mathrm{Si}$ and $\mathrm{Al}$ )-oxygen pairs. The density of dangling bonds of the more weakly bonded pairs is small in alkali-free glass because of the small atom fractions (below 0.5 at\%) of the weaker bonded metals. In contrast, the atom fractions of the alkaline earth metals in the alkali-free glass are much higher, ranging from 3.1 for $\mathrm{Sr}$ to 5.6 for $\mathrm{Ca}$, resulting in higher dangling bond densities. The intermediate values of the bonding energies and high atom fractions of alkaline earth metaloxygen pairs, suggest that large independent ESR signals of the EB-irradiated alkali free glass originate in alkaline earth metal ( $\mathrm{Ca}$ and $\mathrm{Sr}$ )-oxygen pairs. Clearly, EB irradiation generates dangling bonds from alkaline earth metal-oxygen pairs in the glass network structure.

When EB irradiation below 0.0432 MGy generates dangling bonds at the metal ( $\mathrm{Na}, \mathrm{Zn}, \mathrm{K})$-oxygen atomic pairs in alkali free glass, partial relaxation occurs near dangling bonds in the glassy network structure mainly constructed with the stronger bonded ( $\mathrm{Si}$ and $\mathrm{Al}$ )-oxygen pairs. When the interatomic distances of the stronger-bonded metal-oxygen pairs are optimum in the potential curves, relaxation probably increases the bonding energy of the network structure, possibly allowing its rigidity to be enhanced. Both rigidity enhancement and relaxation enhance the impact value, as shown in Figs. 1 and 5.

On the other hand, excess EB irradiation decreases the impact value, as shown in Fig. 5. When the excess irradiation is assumed to form the dangling bonds at strong bonded metal ( $\mathrm{Si}$ and $\mathrm{Al}$ )-oxygen pairs, as well as at the weaker bonded metal ( $\mathrm{Na}$ and $\mathrm{Zn}$ )-oxygen pairs, the excess irradiation also breaks strong bonded pairs in the glass network structure with dangling bond formation. In addition, the excess density of dangling bonds probably accelerates crack growth. Thus, it is explained that excess EB irradiation from 0.1 to $0.43 \mathrm{MGy}$ decreases the impact value.

\section{Conclusion}

In summary, Influences of electron beam irradiation on impact value were studied for alkali free glass. The irradiation increased the impact value. Based on the ESR observation, the impact value enhancement could be explained by stress relaxation induced by increase in density of dangling bonds, which apparently showed different signals of $\mathrm{Na}-\mathrm{O}$ and $\mathrm{Si}-\mathrm{O}$ pairs.

\section{Acknowledgement}

Authors would like to thank Prof. Akira Tonegawa and Dr. Hiroyuki Kobayashi for their useful helps.

\section{REFERENCES}

1) Y. Nishi, T. Toriyama, K. Oguri, A. Tonegawa and K. Takayama: J. Mater. Res. 16 (2001) 1632-1635.

2) Y. Nishi, A. Mizutani, A. Kimura, T. Toriyama, K. Oguri and A. Tonegawa: J. Mater. Sci. 38 (2003) 89-92.

3) Y. Nishi, N. Uchida, A. Kimura, A. Mizutani, K. Oguri and A. Tonegawa: J. Mater. Sci. 38 (2003) 2215-2218.

4) A. Mizutani and Y. Nishi: Mater. Trans. 44 (2003) 1857-1860. 
5) K. Oguri, K. Fujita, M. Takahashi, Y. Omori, A. Tonegawa, N. Honda, M. Ochi, K. Takayama and Y. Nishi: J. Mater. Res. 13 (1998) 33683371.

6) K. Oguri, N. Iwatani, H. Izumi, A. Tonegawa, K. Takayama and Y. Nishi: Proc. of 2nd JAPAN-FRANCE SEMINAR on Intelligent Materials and Structures, (University of Louis Pasteur Strasbourg, France, 1998) pp. 142-144.

7) K. Oguri, N. Iwataka, A. Tonegawa, Y. Hirose, K. Takayama and Y. Nishi: J. Mater. Res. 16 (2001) 553-557.

8) D. L. Griscom and E. J. Friebele: Rad. Effects. 65 (1982) 303-312.

9) D. L. Griscom: The Centenial Memorial Issue of the Ceramic Soc. Jpn. 99 (1991) 923-942.

10) N. Yamaguchi, Kazuya Oguri, Akira Tonegawa and Y. Nishi: J. Jpn. Inst. Met. 68 (2004) 198-201.
11) A. Kadowaki, T. Shinoda, N. Yamaguchi, K. Yamada, K. Oguri, A. Tonegawa and Y. Nishi: J. Jpn. Inst. Met. 68 (2004) 202-205.

12) K. Iwata, K. Yamada, A. Kadowaki, N. Yamaguchi, A. Tonegawa and Y. Nishi: J. Jpn. Inst. Met. 68 (2004) 534-536.

13) R. Christenhusz and L. Reimer: Z. Angew. Phys. (1967) 396-404.

14) T. Nishida and E. Yasuda: Evaluation of dynamic properties of ceramics (in Japanese: Ceramics no rikigaku tokusei hyouka), Nikkan Kogyou Shimbun Sha, (1986) 50-51.

15) W. S. Freiman: Elasticity and Strength in Glasses, GLASS; SCIENCE AND TECHNOLOGY, Vol. 5 (Ed. by R. D. Uhlmann and J. N. Kreidl, Academic Press 5 1980) pp. 63-65.

16) J. B. Pedley and E. M. Marshall: J. Phys. Chem. Ref. Data 12 (1983) 967-1031. 